Teknika $12(2): 1-7$

JURNAL TEKNIKA
ISSN: 0854-3143
e-ISSN: 2622-3481
Journal homepage: http://jurnal.polsri.ac.id/index.php/teknika
Journal Email: teknika@polsri.ac.id

\title{
Sistem Informasi Elektronik Mading (E-Mading) UKM dan Fakultas Ilmu Komputer IIB Darmajaya
}

\author{
Indera *1, Hendi Ramasudha ${ }^{2}$ \\ 1,2 Jurusan Sistem Informasi/Institut Informatika dan Bisnis Darmajaya; Jl. Z.A. Pagar Alam \\ No.93, Bandar Lampung-Indonesia 35142 Telp.(0721)787214. Fax. (0721)700261 \\ e-mail: *1 indera@darmajaya.ac.id, ${ }^{2}$ hendiramasudha@darmajaya.ac.id
}

\begin{abstract}
Abstrak
Pemberitahuan informasi kegiatan rutin Akademik, Badan Eksekutif Mahasiswa, Majelis Perwakilan Mahasiswa, Himpunan Mahasiswa, Unit Kegiatan Mahasiswa serta lainnya di Darmajaya diumumkan melalui mading (majalah dinding). Pemberitahuan informasi menggunakan mading dirasa kurang efisien dan efektif dikarenakan malasnya mahasiswa/i untuk melihat dan membaca informasi tersebut melalui mading, kurang menariknya papan mading, dan kertas yang sering di rusak oleh pihak yang tidak bertanggung jawab serta penempatan papan mading yang dirasa kurang strategis sehingga adanya informasi yang kurang jelas.Metode pengembangan sistem dari aplikasi e-mading yang dibangun menggunakan metode RUP (Rational Unified Process) dengan tools perencanaan menggunakan UML (Unified Modeling Language) yang terdiri dari use case diagram, activity diagram, class diagram dan squence diagram. Aplikasi e-mading yang dibangun dapat memberikan infromasi mengenai mading dari tiap-tiap organisasi HIMA, UKM, Fakultas Ilkom (Sistem Informasi) dan Kemahasiswaan di IIB Darmajaya, sehingga dapat memudahkan pengguna memperoleh informasi mengenai kegiatan kampus, informasi pembayaran kuliah, lowongan pekerjaan, serta informasi mengenai kegiatan seminar atau workshop yang ada di IIB Darmajaya.
\end{abstract}

Kata kunci-E-Mading, Android, RUP (Rational Unified Process), UML (Unified Modeling Language)

\begin{abstract}
Darmajaya is one of the leading private higher education institutions in Lampung. Information about academics. Student executive board. Student representative assembly, studens associtation. Student activity unit. and the others in darmajaya was announced on wall magazine. The information using wall magazine was less efficient and effective because the student had no time to see and read the informationon wall magazine moreover. The wall magazine was less attractive, the paper was easily damaged, the information was limited and not updated, and the wall magazine location was less strategis to see so that information was not clear. Therefore a wall magazine application with the smartphone teechnology development must be used. Development-system method for e-wall magazine application was built through
\end{abstract}


RUP ( Relational United Process) method by using UML (Unifed Modeling Language) consisting of use case diagram. Activity diagram. Class diagram. And Squance diagram. E-wall magazine application can provide information about student representative assemby. Small Medium Enterprise. Computer Science Faculty.and student activity at IIB Darmajaya so that it is able to facilitate the user to get information about campus activities, college payment information job vacancy. And information about seminar or workhshop activities at IIB Darmajaya.

Keywords - E-Mading Android, RUP (Relational Unifed Process) UML (Unifed Modeling Language)

\section{PENDAHULUAN}

Mading adalah salah satu media komunikasi serta informasi massa tulis, yang penyajiannya biasanya dipajang pada media dinding atau sejenisnya. Pemberitahuan informasi mengenai kegiatan-kegiatan akademik ataupun non akademik yang berkaitan dengan kampus menggunakan mading dirasa kurang efisien dan efektif. Dikarenakan malasnya mahasiswa/i untuk melihat dan membaca informasi tersebut melalui mading, kurang menariknya papan mading, dan kertas yang sering di rusak oleh pihak yang tidak bertanggung jawab serta penempatan papan mading yang dirasa kurang strategis sehingga adanya informasi yang kurang jelas, informasi mading atau artikel yang di sampai kan terbatas dan susah meng update informasi dalam waktu yang cukup singkat bagi pihak informan yang mengakibatkan informasi tersebut tidak update karna tidak ada kejelasan waktu.

Tujuan penelitian yang di lakukan adalah untuk membangun aplikasi emading UKM dan Fakultas Ilmu Komputer agar informasi yang di publikasikan dapat lebih cepat tersampai kan kepada seluruh mahasiswa/i IIB DARMAJAYA serta efisiensi waktu dan pendanaan bagi pengelola madding.

Penelitian ini akan memberikan manfaat sebagai berikut:

a. Meningkatkan pelayanan informasi madding di kampus IIB Darmajaya

b. Mempermudah publikasi informasi berupa brosur atau pamflet dan informasi lainnya.

c. Mempermudah pengawasan informasi yang di publikasikan. d. Menghemat biaya dan waktu pembuatan brosur atau pampflet kertas menjadi elektronik.

e. Membantu mahasiswa/i dalam mencari informasi yang cepat mengenai kegiatan yang ada di IIB DARMAJAYA.

\section{METODE PENELITIAN}

Metode penelitian yang digunakan dalam pembuatan Sistem Informasi Elektronik Mading (E-Mading) UKM dan Fakultas Ilmu Komputer Pada IIB Darmajaya Berbasis Android adalah sebagai berikut:

\subsection{Metode Pengumpulan Data}

Pengumpulan data yang digunakan dalam menyusun serta melengkapi data adalah dengan cara observasi, wawancara dan studi pustaka.

a. Observasi

Pengamatan langsung diadakan untuk memperoleh data yang dilakukan pada instansi terkait dengan penelitian yang dilakukan di IIB Darmajaya.

b. Wawancara

Wawancara dilakukan dengan cara berkomunikasi langsung dengan UKM atau orang yang memberikan informasi di mading mengenai hal-hal yang berkaitan dengan pemberitahuan informasi tersebut.

c. Studi Pustaka

Studi pustaka dilakukan untuk memperoleh data dan informasi dengan membaca berbagai bahan penulisan, karangan ilmiah serta sumber-sumber

Teknika Vol. 12, No. 02, Desember 2018: $1-7$ 
lain mengenai permasalahan yang berhubungan dengan penulisan.

\subsection{Metode Pengembangan Sistem}

Unified Process atau dikenal juga dengan proses iteratif dan inkremental merupakan sebuah proses pengembangan perangkat lunak yang dilakukan secara iteratif (berulang) dan inkremental (bertahap dengan proses menaik). Iteratif bisa dilakukan di dalam setiap tahap atau iteratif tahap pada proses pengembangan perangkat lunak untuk menghasilkan perbaikan fungsi yang inkremental, dimana setiap iterasi akan memperbaiki iterasi berikutnya (Rosa, 2011). Salah satu Unified Process yang terkenal adalah RUP (Rational Unified Process).

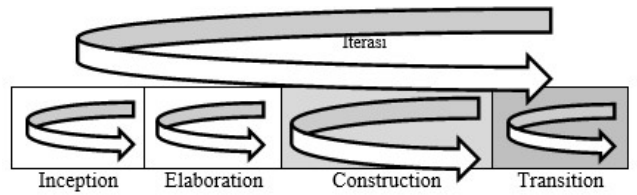

Gambar 1. Alur Hidup RUP

a. Permulaan (Inception)

Permulaan berawal dari menentukan tempat penelitian yang diadakan.Setelah menentukan tempat penelitian, tahap selanjutnya adalah melakukan analisa permasalahan. Pemberitahuan informasi mengenai kegiatan-kegiatan akademik ataupun non akademik yang berkaitan dengan kampus menggunakan mading dirasa kurang efisien dan kurang efektif. Setelah didapat pemecahan permasalahan tersebut, maka tahap selanjutnya adalah merencanakan pembuatan aplikasi mading UKM dan Fakultas Ilmu Komputer IIB Darmajaya.

b. Perencanaan/Perluasan (Elaboration)

Tahapan ini lebih mengarah pada analisis, desain/perancangan dan implementasi. Sebelum beranjak ketahapan perancangan, maka dilakukan terlebih dahulu analisa sistem berjalan mengenai pemberian informasi UKM dan Fakultas Ilmu Komputer melalui mading. Analisa sistem berjalan dilakukan guna menganalisa sistem yang berjalan dengan menggunakan pemodelan UML berupa use case. Perancangan sistem yang diusulkan terdiri dari use case, activity diagram, perancangan database, perancangan struktur menu aplikasi dan perancangan input/output. Tahap pengodean dilakukan setelah perancangan. Pengodean dilakukan untuk mengimplementasikan sistem perangkat lunak yang sudah dirancang pada tahapan desain sebelumnya. Pengodean dilakukan menggunakan bahasa pemograman Java dan editor Android Studio serta database MySQL.

c. Konstruksi (Construction)

Tahapan ini mengarah pada proses pengujian aplikasi yang dibangun. Pengujian dilakukan untuk menguji perangkat lunak yang seiring dengan pembuatan kode program. Hal ini dilakukan untuk meminimalisir kesalahan (error) dan memastikan keluaran yang dihasilkan sesuai dengan yang diinginkan.

d. Transisi (Transition)

Tahapan ini mengarah ke instalasi aplikasi yang dibangun. Aplikasi mading berbasis Android yang dibangun berformat apk dan di upload ke Google Play Store.

\section{HASIL DAN PEMBAHASAN}

\subsection{Hasil}

Hasil dari penelitian yang diadakan berupa aplikasi e-mading IIB Darmajaya. Isi di dalam aplikasi tersebut berupa informasi mading dari UKM (Unit Kegiatan Mahasiswa/i), Fakultas Ilmu Komputer dan BAAK. Adapun pembahasan dalam tahapan pembuatan aplikasi tersebut dijelaskan secara rinci pada bagian sub bab pembahasan sesuai dengan metode yang digunakan.

\subsection{Pembahasan}

Pembahasan mengenai proses pembuatan aplikasi e-mading IIB Darmajaya dengan metode pengembangan sistem RUP (Rational Unified Process) yang terdiri dari permulaan(inception), perluasan/ perencanaan (elaboration), konstruksi (construction), dan transisi (transition) adalah sebagai berikut : 


\subsubsection{Permulaan (Inception)}

Permulaan berawal dari menentukan tempat penelitian yang diadakan. Penelitian ini dilaksanakan di IIB Darmajaya. Setelah menentukan tempat penelitian, tahap selanjutnya adalah melakukan analisa permasalahan. Permasalahan yang terjadi di IIB Darmajaya mengenai mading adalah malasnya mahasiswa/i untuk melihat dan membaca informasi tersebut melalui mading, kurang menariknya papan mading, dan kertas yang sering di rusak oleh pihak yang tidak bertanggung jawab serta penempatan papan mading yang dirasa kurang strategis sehingga adanya informasi yang kurang jelas, informasi mading atau artikel yang disampaikan terbatas dan susah meng-update informasi dalam waktu yang cukup singkat bagi pihak informan yang mengakibatkan informasi tersebut tidak update karna tidak ada kejelasan waktu. Maraknya penggunaan smartphone android dikalangan mahasiswa/i IIB Darmajaya, maka didapatkan pemecahan masalah dengan membuat aplikasi e-mading IIB Darmajaya berbasis android. Setelah didapat pemecahan permasalahan tersebut, maka tahap selanjutnya adalah merencanakan pembuatan aplikasi android e-mading IIB Darmajaya.

\subsubsection{Perluasan/Perencanaan (Elaboration)}

Tahapan ini lebih mengarah pada analisis, desain atau perancangan dan implementasi. Sebelum beranjak ketahapan perancangan, maka dilakukan terlebih dahulu analisa sistem berjalan mengenai pemberitahuan informasi mading kepada mahasiswa/i IIB Darmajaya. Analisa sistem berjalan dilakukan guna menganalisa sistem yang berjalan dengan menggunakan pemodelan UML berupa use case. Analisa terhadap sistem yang berjalan, nantinya akan menghasilkan usulan sistem yang baru.

\subsection{Analisa Sistem Berjalan}

Analisa sistem berjalan mengenai pemberitahuan informasi mading UKM, Fakultas Ilmu Komputer dan BAAK kepada mahasiswa/i IIB Darmajaya adalah seperti dijelaskan pada use case Gambar 2.

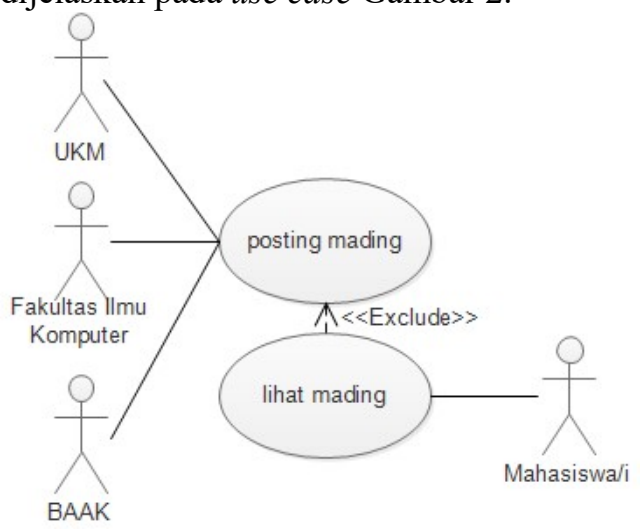

Gambar 2 Use Case Sistem Berjalan

\subsection{Perancangan Sistem Diusulkan}

Adapun sistem yang diusulkan adalah sebuah aplikasi e-mading IIB Darmajaya yang dapat mengatasi permasalahan yang ada. Perancangan sistem yang diusulkan, dapat dilihat pada Gambar 3.

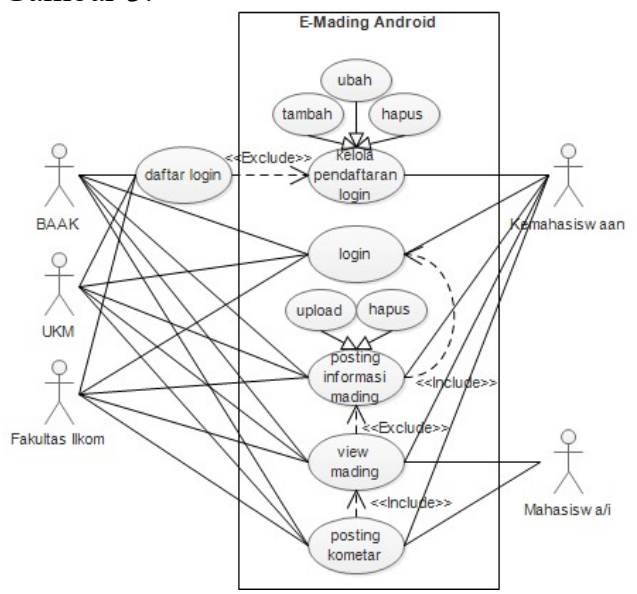

Gambar 3 Use Case E-Mading Diusulkan

\subsection{Activity Diagram Sistem Diusulkan}

Activity diagram menggambarkan berbagai alir aktivitas dalam sistem yang sedang dirancang. Perancangan activity diagram yang terdapat pada aplikasi EMading yang mengacu pada use case yang sudah dibuat sebelumnya adalah sebagai berikut :

a. Activity Diagram Kelola Pendaftaran Login

Dari skenario use case pendaftaran login, maka activty diagram kelola

Teknika Vol. 12, No. 02, Desember 2018 : 1 - 7 
pendaftaran login digambarkan pada Gambar 4

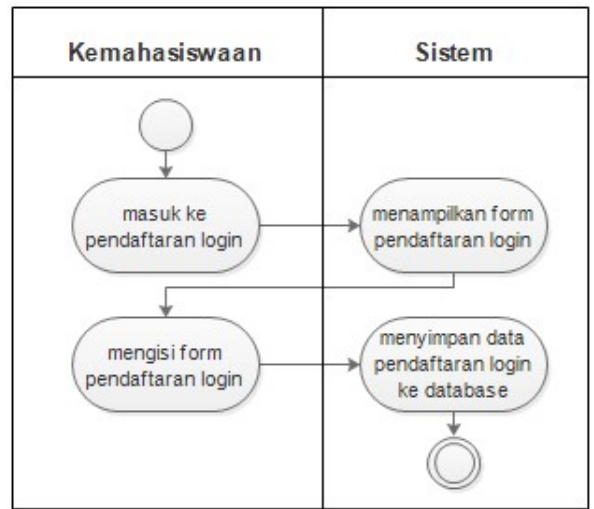

Gambar 4 Activity Diagram Kelola Pendaftaran Login

b. Activity Diagram Login

Dari skenario use case login, maka activty diagram login digambarkan pada Gambar 5.

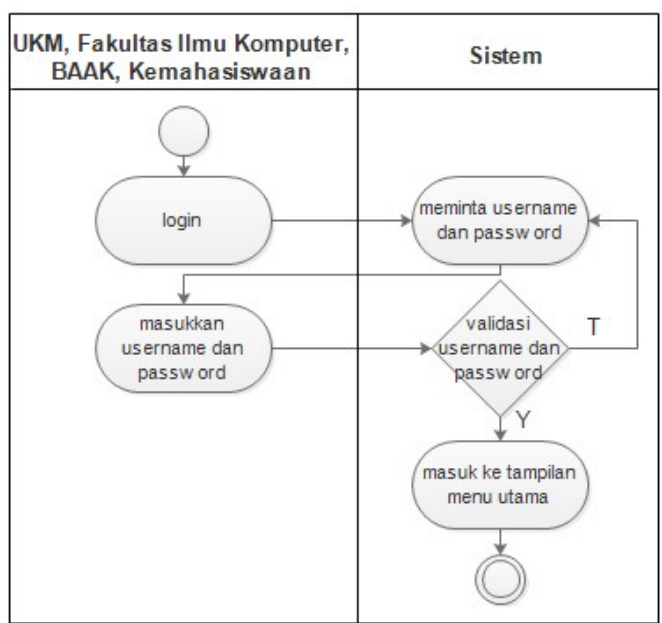

Gambar 5 Activity Diagram Login

c. Activity Diagram Posting Informasi Mading

Dari skenario use case posting informasi mading, maka activty diagram posting informasi mading digambarkan pada Gambar 6.

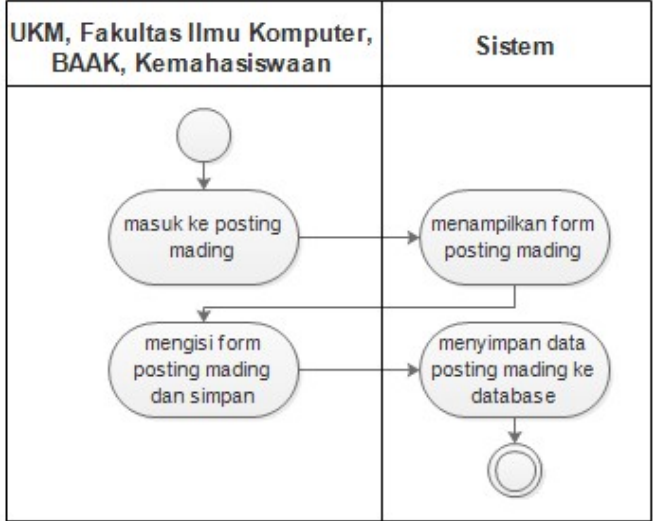

Gambar 6 Activity Diagram Posting Informasi Mading

d. Activity Diagram View Mading

Dari skenario use case view mading, maka activty diagram view mading digambarkan pada Gambar 7.

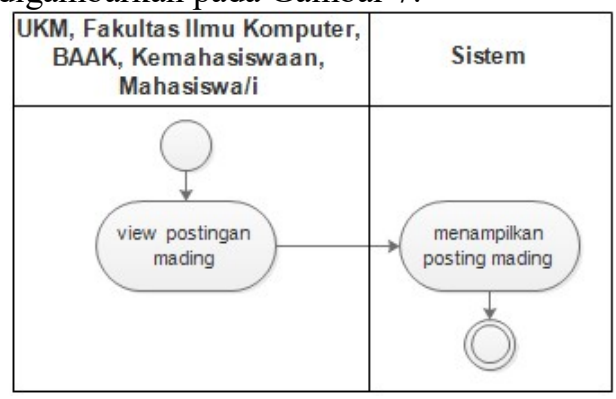

Gambar 7 Activity Diagram View Mading

e. Activity Diagram Posting Komentar

Dari skenario use case posting komentar, maka activty diagram posting komentar digambarkan pada Gambar 8.

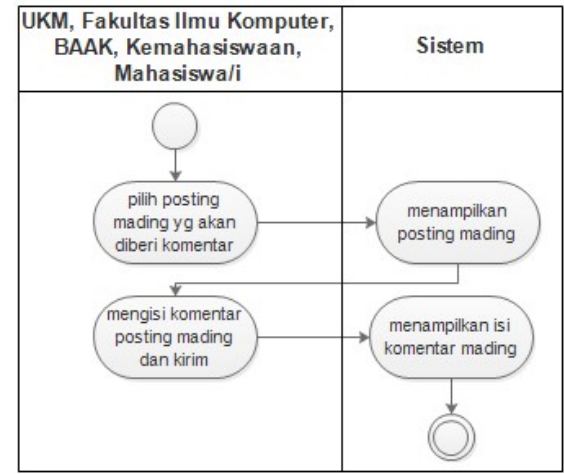

Gambar 8 Activity Diagram Posting Komentar

\subsection{Perancangan Database}

Perancangan tabel database pada aplikasi android iqro adalah seperti pada Gambar 9. 


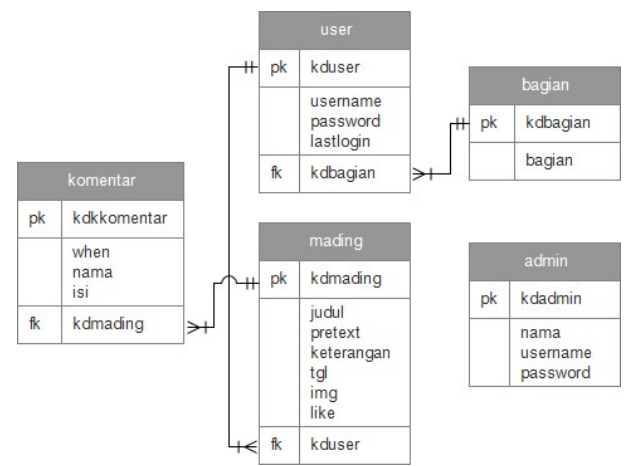

Gambar 9 Perancangan Database

3.7 Implementasi Menu Input/Output Admin

Implementasi dari menu input/output yang dapat diakses oleh admin.Adapun menu input/output terdiri dari:

a. Implementasi Menu Utama Admin

b. Implementasi Menu Input/Output User

c. Implementasi Menu Input/Output Bagian

\subsection{Implementasi Menu Input User dan} Admin

Implementasi menu input/output dengan hak akses user dan admin adalah sebagai berikut :

a. Implemetasi Menu Input Login Aplikasi

b. Implementasi Menu Input Posting Mading

\subsection{Implementasi Menu Input/Output} Aplikasi E-Mading

a. Implementasi Menu Utama Aplikasi

b. Implementasi Menu Output Mading

c. Implementasi Menu Input/Output Komentar

\subsection{Konstruksi (Construction)}

Tahapan ini mengarah pada proses pengujian aplikasi yang dibangun yang berbarengan dengan implementasi. Pengujian dilakukan untuk menguji perangkat lunak yang seiring dengan pembuatan kode program. Hal ini dilakukan untuk meminimalisir kesalahan (error) dan memastikan keluaran yang dihasilkan sesuai dengan yang diinginkan.

\subsection{Transisi (Transition)}

Tahapan ini mengarah ke instalasi aplikasi yang dibangun. Aplikasi e-mading berbasis android yang dibangun berformat .apk dan dihosting ke internet.

\section{KESIMPULAN}

Berdasarkan proses pembangunan aplikasi E-Mading berbasis android yang dimulai dari tahap analisis hingga implementasi, maka dapat ditarik kesimpulan sebagai berikut :

a. Aplikasi E-Mading yang dibangun dapat memberikan infromasi mengenai mading dari tiap-tiap organisasi HIMA, UKM, Fakultas Ilkom (Sistem Informasi) dan Kemahasiswaan di IIB Darmajaya, sehingga dapat memudahkan pengguna memperoleh informasi mengenai kegiatan kampus, informasi pembayaran kuliah, lowongan pekerjaan, serta informasi mengenai kegiatan seminar atau workshop yang ada di IIB Darmajaya.

b. Terdapat tombol like dan komentar di tiap informasi mading, sehingga dapat mempengaruhi tingkat kesukaan atau kepentingan dari pembaca mading terhadap informasi mading yang diunggah.

c. Terdapat notifikasi jika ada unggahan mengenai informasi mading baru atau komentar pada informasi mading.

\section{SARAN}

Agar aplikasi E-Mading berbasis android lebih sempurna, maka pada penelitian berikutnya disarankan sebagai berikut :

a. Menambahkan peta lokasi lowongan pekerjaan di dalam aplikasi E-Mading agar dapat menunjukkan lokasi lowongan kerja jika user mengunggah berita informasi mading mengenai lowongan pekerjaan.

b. Menambahkan field jumlah pengunjung untuk dapat mengetahui seberapa sering aplikasi E-Mading diakses.

Teknika Vol. 12, No. 02, Desember 2018: $1-7$ 


\section{UCAPAN TERIMA KASIH}

Penulis mengucapkan terima kasih kepada Tim Redaksi Jurnal Teknika Politeknik Negeri Sriwijaya yang telah memberi memberi kesempatan, sehingga artikel ilmiah ini dapat diterbitkan.

\section{DAFTAR PUSTAKA}

[1] A.S, Rosa \& Salahudin, M. 2011. Modul Pembelajaran Rekayasa Perangkat Lunak (Terstruktur dan Berorientasi Objek), Modula, Bandung.

[2] Avestro, Joyce. 2007. Pengembangan Peragkat Mobile : Java Education Network Indonesia (JENI).

[3] Kadir, Abdul. 2013. Pemograman Aplikasi Android. Andi, Yogyakarta.

[4] Kadir, Abdul. 2014. Pengenalan Sistem Informasi Edisi Revisi. Andi Offset, Yogyakarta.

[5] Prabowo, Eric Cundomanik., Puspa, Lily Dewi \& Andjarwirawan, Juntinus. 2016.

[5] Aplikasi Survei Berbasis Android. Jurnal Teknik Informatika, Universitas Kristen Petra, Surabaya.

[7] Solichin, Achmad. 2016. Pemograman Web dengan PHP dan MySQL. E-Book diakses dari https://www.researchgate.net/publicati on/236885805_Pemrograman_Web_de ngan_PHP_dan_MySQL, Tanggal 20 Agustus 2017, Pukul 08.33 WIB. 